\title{
Originals
}

\section{Coagulation Abnormalities in Diabetic Coma before and 24 Hours after Treatment}

\author{
E. H. McLaren, D. R. Cullen, and M. J. Brown \\ Royal Hospital and Northern General Hospital, Sheffield, England
}

\begin{abstract}
Summary. A coagulation screen consisting of measurement of the prothrombin time, thrombin time, kaolin cephalin clotting time, platelet count, plasma fibrinogen level, fibrin degradation products and ethanol gelation test was performed on 24 patients with impairment of consciousness due to acute diabetic metabolic decompensation at the start of treatment and 24 hours later. 22 out of 24 patients showed at least one coagulation abnormality on admission of which the commonest were a prolonged prothrombin time, shortened kaolin cephalin clotting time and raised plasma fibrinogen level. After 24 hours of treatment these values were more normal but 20 out of 22 patients still displayed some abnormality. 15 patients had two or more coagulation abnormalities on admission including 3 patients with haematological abnormalities suggestive of disseminated intravascular coagulation. This group was older and had higher blood ureas than those with fewer abnormalities, but plasma glucose, sodium, potassium and bicarbonate levels were similar in both groups of patients. All 5 patients with hyperosmolar non-ketotic coma and all 3 patients who died without recovering consciousness had two or more coagulation abnormalities on admission.
\end{abstract}

Key words: Diabetic coma, coagulation abnormalities, disseminated intravascular coagulation.

The pathogenesis of the neurological manifestations of diabetic coma is uncertain [1]. It has, however, been suggested that cerebral intravascular coagulation may be responsible for some of these features [2].
Coagulation abnormalities consisting of raised fibrinogen and factor VIII levels [3, 4], reduced cephalin times [3] and increased platelet adhesiveness $[4,5]$, are present in well controlled diabetic patients. In addition, disseminated intravascular coagulation occasionally occurs in patients in diabetic coma $[5,6]$, and pathological study of the brains of patients dying from this condition has shown platelet thrombi in cerebral vessels [2].

It is not known, however, whether the already abnormal coagulation pattern of diabetics is further upset during all episodes of diabetic coma, although one study showed that fibrinogen levels were raised and that fibrinolytic activity was increased under these circumstances [7].

The present study was therefore undertaken to determine the incidence and severity of coagulation abnormalities in diabetic coma and to see whether these abnormalities were related to the complications or outcome of the episode.

\section{Patients and Methods}

24 patients with impairment of consciousness related to acute diabetic metabolic decompensation were studied. Clinical details and initial biochemistry are shown in Table 1.22 patients were unselected consecutive admissions to Medical Units, but in patients 21 and 23 , clinical evidence of bleeding led to performance of coagulation tests and inclusion in the study. We regarded patients with an initial venous bicarbonate level of less than $15 \mathrm{mmol} / 1$. and marked ketonuria as having diabetic ketoacidosis 19 patients came into this category. The 4 patients without significant acidosis or ketonuria were classified as hyperosmolar nonketotic comas. In patient 24 a diagnosis of lactic acidosis was made on the basis of systemic acidosis without ketonuria. Raised plasma lactate levels were demonstrated in this patient. The mean age of the patients was 47 years with a range of $17-81$ years.

A coagulation screen consisting of the prothrombin time (PT), thrombin time (TT), kaolin cephalin clotting time (KCCT), 
Table 1. Clinical features of the diabetic patients

\begin{tabular}{|c|c|c|c|c|c|c|c|c|}
\hline \multirow[t]{2}{*}{ No. } & \multirow{2}{*}{$\begin{array}{l}\text { Age } \\
\text { (years) }\end{array}$} & \multirow{2}{*}{$\begin{array}{l}\text { Duration of } \\
\text { diabetes } \\
\text { (years) }\end{array}$} & \multirow{2}{*}{$\begin{array}{l}\text { Type } \\
\text { of } \\
\text { coma }\end{array}$} & \multicolumn{3}{|c|}{ Initial investigations $(\mathrm{mmol} / \mathrm{l})$} & \multirow[t]{2}{*}{ Complications } & \multirow[t]{2}{*}{ Outcome } \\
\hline & & & & $\begin{array}{l}\text { Blood } \\
\text { sugar }\end{array}$ & $\mathrm{HCO}_{3}$ & Urea & & \\
\hline 1 & 20 & 6 & KA & 32 & 8 & 9.5 & & Rec. \\
\hline 2 & 45 & New & $\mathrm{KA}$ & $>50$ & 8 & 12 & & Rec. \\
\hline 3 & 71 & New & $\mathrm{KA}$ & 48 & 5 & 9 & & Rec. \\
\hline 4 & 56 & New & $\mathrm{KA}$ & 57 & 7 & 26 & $\begin{array}{l}\text { Acute panc. } \\
\text { G.I. haem }\end{array}$ & Died \\
\hline 5 & 81 & 40 & $\mathrm{KA}$ & 29 & 7 & 14 & & Rec. \\
\hline 6 & 42 & 20 & $\mathrm{KA}$ & 62 & 8 & 22 & & Rec. \\
\hline 7 & 17 & 4 & $\mathrm{KA}$ & 34 & 7 & 9.6 & & Rec. \\
\hline 8 & 67 & 18 & $\mathrm{KA}$ & 40 & 9 & 35 & $\begin{array}{l}\text { Chronic renal } \\
\text { failure }\end{array}$ & Died \\
\hline 9 & 17 & 6 & $\mathrm{KA}$ & 36 & $<5$ & 11 & & Rec. \\
\hline 10 & 40 & 15 & $\mathrm{KA}$ & 21 & 2 & 11 & $\begin{array}{l}\text { Diarrhoea and } \\
\text { vomiting }\end{array}$ & Rec. \\
\hline 11 & 18 & 2 & $\mathrm{KA}$ & 39 & 5 & 9.6 & & Rec. \\
\hline 12 & 81 & 40 & $\mathrm{KA}$ & 26 & 13 & 10 & Chest infection & Rec. \\
\hline 13 & 21 & New & KA & 12 & 8 & 4 & & Rec. \\
\hline 14 & 34 & 0.5 & $\mathrm{KA}$ & 18 & 5 & 5 & Skin sepsis & Rec. \\
\hline 15 & 51 & New & $\mathrm{KA}$ & 25 & 10 & 8 & & Rec. \\
\hline 16 & 28 & New & $\mathrm{KA}$ & 22 & 2 & 6.4 & & Rec. \\
\hline 17 & 34 & 0.5 & $\mathrm{KA}$ & 18 & 4 & 8 & Vomiting & Rec. \\
\hline 18 & 54 & New & $\mathrm{KA}$ & 28 & 5 & 15 & $\begin{array}{l}\text { ? Urinary tract } \\
\text { infection }\end{array}$ & Rec. \\
\hline 19 & 64 & New & $\mathrm{KA}$ & 34 & 8 & 23 & Scrotal gangrene & Died \\
\hline 20 & 52 & New & $\mathrm{HO}$ & 47 & 19 & 22 & & Rec. \\
\hline 21 & 57 & New & $\mathrm{HO}$ & 53 & 25 & 20 & $\begin{array}{l}\text { Gram negative } \\
\text { septicaemia }\end{array}$ & Rec. \\
\hline 22 & 66 & New & $\mathrm{HO}$ & 32 & 16 & 8 & Diarrhoea & Rec. \\
\hline 23 & 66 & 25 & $\mathrm{HO}$ & 26 & 19 & 12 & $\begin{array}{l}\text { Acute L.V.F. } \\
\text { M.I. }\end{array}$ & Died \\
\hline 24 & 54 & New & $\mathrm{HO} / \mathrm{LA}$ & 84 & 16 & 30 & $\begin{array}{l}\text { Thrombus occluding } \\
\text { upper aorta }\end{array}$ & Died \\
\hline
\end{tabular}

$\mathrm{KA}=$ Ketoacidotic coma; $\mathrm{HO}=$ Hyperosmolar non-ketotic coma; LA $=$ Lactic acidosis Rec. $=$ Recovered

platelet count, plasma fibrinogen level, fibrin degradation products measured as fibrinogen/fibrin related antigen (FDP's), and ethanol gelation test was performed at the time of admission and 24 hours after the start of treatment. Patients were treated by conventional fluid and electrolyte replacement. Soluble insulin was given either with a constant infusion pump, 6 units hourly, or by repeated intramuscular injection of 10 units hourly. Bicarbonate was not given to any patient, and low dose heparin was used in cases 19 and 24.

The prothrombin time, thrombin time and kaolin cephalin clotting time were performed according to the methods described in Dacie and Lewis [8]. Platelets were counted in a Technicon Platelet Counter. Fibrinogen/fibrin related antigen was assayed by the Latex Agglutination method (Thrombo-Wellcotest, Wellcome Reagents Ltd., Beckenham, Kent).

Fibrinogen was quantitated by the method of Ellis and Stransky [10] or a modification of this technique [11].

Normal values for this laboratory were as follows:

Prothrombin Time: British Corrected Ratio (BCR) [9]: 1-1.25.

Thrombin Time: Within 2 secs. of normal control pool.

Thrombin Ratio (simple ratio of patient to control): 0.82-1.18.

Kaolin Cephalin Clotting Time: Within 7 secs. of normal control pool.
Kaolin Cephalin Clotting Ratio (simple ratio of patient to control): $0.84-1.16$ (a ratio of less than 1.0 indicates a shortened KCCT).

Platelet Count: $150 \times 10^{9} / 1-400 \times 10^{9} / 1$.

Plasma Fïbrinogen Level: $2.5-4 \mathrm{~g} / \mathrm{I}$.

Fibrinogen/Fibrin Related Antigen: Less than $8 \mathrm{ug} / \mathrm{ml}$.

Ethanol Gelation Test: Negative.

\section{Results}

The detailed results of the coagulation screens performed on these patients at 0 and 24 hours are shown in Table 2 and the percentage of abnormal results in Table 3. The commonest abnormalities were a prolonged PT, shortened KCCT and high fibrinogen level at 0 hours. By 24 hours the KCCT and fibrinogen levels were still abnormal in many cases.

22 out of 24 patients had one or more abnormal results in the screen at 0 hours, and 20 out of 22 still 


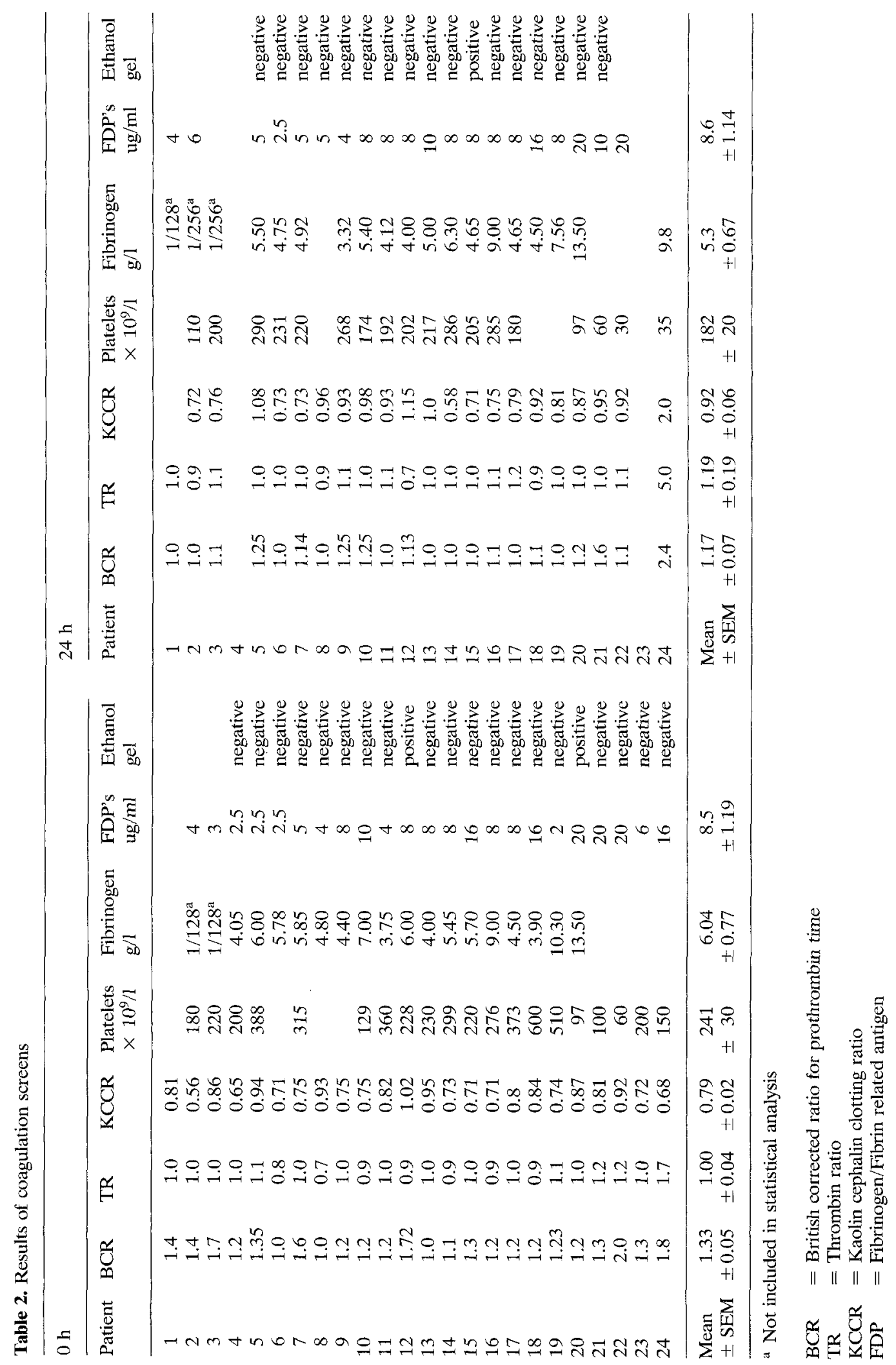


Table 3. Percentage abnormal results

\begin{tabular}{rrrrrrrrr}
\hline & $\begin{array}{l}\text { Total } \\
\text { no. }\end{array}$ & BCR & TT & KCCT & Platelets & Fibrinogen & FDP's & Ethanol gel \\
\hline $0 \mathrm{~h}$ & 24 & $42 \%$ & $13 \%$ & $71 \%$ & $15 \%$ & $82 \%$ & $17 \%$ & $4 \%$ \\
$24 \mathrm{~h}$ & 22 & $9 \%$ & $8 \%$ & $45 \%$ & $23 \%$ & $68 \%$ & $9 \%$ & $8 \%$ \\
\hline
\end{tabular}

had an abnormal result 24 hours after the start of treatment.

Those patients with two or more coagulation abnormalities at the time of presentation were older (mean \pm SEM $56 \pm 5$ years) than subjects with one or fewer abnormalities (mean \pm SEM $34 \pm 6$ years). All the patients with hyperosmolar coma had two or more abnormalities and all the deaths without recovery of consciousness occurred in this group. Of the biochemical parameters measured (blood glucose, urea, sodium, potassium, chloride and bicarbonate) only the blood urea was significantly higher in the group with two or more coagulation abnormalities (mean \pm SEM $16.8 \pm 2 \mathrm{mmol} / \mathrm{l}$.) compared with those with one or fewer (mean \pm SEM $9.7 \pm$ $2.4 \mathrm{mmol} / 1$.).

The definition of disseminated intravascular coagulation (DIC) is difficult without histological evidence from the examination of tissue. It was felt, however, that patients with evidence of bleeding into the skin and coagulation abnormalities consisting of thrombocytopenia, raised FDP's and some evidence of the consumption of clotting factors (raised PT or TT) showed presumptive evidence of DIC. 3 patients $[21,22,24]$ came into this category. In 1 patient, no precipitating cause could be found, but the others had a gram negative septicaemia and a thrombus occluding the upper aorta respectively. 1 further patient [19], who had Fournier's gangrene of the scrotum developed similar coagulation abnormalities 60 hours after admission. At postmortem, this patient's brain showed extensive platelet thrombi in the small blood vessels.

\section{Deaths}

3 patients $[4,19,24]$ died without recovering consciousness from their diabetic coma, although at the time of death their blood sugar and electrolytes were normal in all cases. One of these was the patient with aortic thrombosis and the other two had acute pancreatitis and Fournier's gangrene of the scrotum. All these patients had shown two or more abnormal results in the coagulation screen on admission.

\section{Discussion}

Abnormalities of coagulation in diabetic coma appear to be the rule rather than the exception. There was a tendency for these tests to be more abnormal in patients who died, but many patients made an uninterrupted recovery in spite of marked abnormalities in the coagulation screen. The commonest abnormalities seen in this series were similar in type to those found in the ambulant diabetic. The Fibrinogen levels found were, however, much higher than those reported in a series of well diabetics where the mean levels have been about $4 \mathrm{~g} / 1$. [3, 4]. The shortened KCCT is probably due to the increased levels of factor VIII previously reported in comatose [2] and ambulant [4] diabetics. The prothrombin time in well controlled diabetics is said to be normal [3], although a slight reduction in prothrombin activity in maturity onset diabetes has been reported [12].

The pattern of abnormalities found in these patients is difficult to interpret in terms of known coagulopathies. 3 cases out of 24 is a high incidence of probable DIC, although this is partly due to selection since spontaneous bleeding led to the initial performance of coagulation tests in two instances.

In at least one of the cases of DIC, no precipitating cause could be found, confirming the observations $[2,6]$, that DIC may occur de novo in diabetic coma. The normal platelet counts and FDP's, however, make it unlikely that subclinical DIC is occurring in the majority of patients.

It is possible that these coagulation abnormalities are not specific to diabetes but are merely secondary to any profound metabolic abnormality. They would, however, be expected to be more severe in the diabetic because of pre-existing coagulation abnormalities.

The data from this study failed to show any correlation between the height of the blood sugar or the severity of the acidosis and the number of coagulation abnormalities. More abnormal results were, however, seen in older patients and those with higher blood ureas which may have reflected a greater degree of dehydration. 
From a small study it is not however possible to answer the important question as to whether coagulation abnormalities contribute to the mortality or morbidity of diabetic coma. Cerebral oedema and major vascular occlusions account for the majority of the residual mortality, estimated at $2.5 \%$, which would be left if deaths in ketoacidosis from metabolic mismanagement or undiscovered infection could be eliminated [13]. There is still no universal agreement as to the cause of these complications but the findings of this study would indicate that abnormal coagulation is to be expected in diabetic coma, although further work is required to see whether this has a primary role in the cerebral problems found in these patients.

Acknowledgements. We would like to thank Dr. F. J. Flint for permission to study patients under his care, Dr. W. R. Timperley for the neuropathological data, Dr. F. E. Preston for laboratory data and Miss L. Rowlands for technical assistance.

\section{References}

1. Guisado, R., Arieff, A. I.: Neurological manifestations of diabetic coma. Metabolism 24, 665-679 (1975)

2. Timperley, W.R., Preston, F.E., Ward, J.D.: Cerebral intravascular coagulation in diabetic ketoacidosis. Lancet 1974 I, 952-956

3. Egeberg, O.: The blood coagulability in diabetic patients. Scand. J. Clin. Lab. Invest. 15, 533-538 (1963)

4. Mayne, E. E., Bridges, J. M., Weaver, J. A.: Platelet adhesiveness, plasma fibrinogen and factor VIII levels in diabetes mellitus. Diabetologia 6, 436-440 (1970)
5. Kwaan, H. C., Colwell, J. A., Suwanwela, N.: Disseminated intravascular coagulation in diabetes mellitus with reference to the role of increased platelet aggregation. Diabetes $\mathbf{2 1}$, 108-113 (1972)

6. Nicholson, G., Tomkin, G. H.: Successful treatment of disseminated intravascular coagulopathy complicating diabetic coma. Br. Med. J. 1974 IV, 450

7. Bellet, S., Sandber, H., Tsitouris, G., Muller, O., Schraeder, J.: Alteration in fibrinolytic parameters during recovery from diabetic acidosis. Metabolism 10, 429-438 (1961)

8. Dacie, J. V., Lewis, S. M.: Practical haematology. 5th ed., pp 314-403. London: Churchill 1975

9. Biggs, R., Denson, K.W. E.: Standardisation of the one-stage prothrombin time for control of anticoagulant therapy. $\mathrm{Br}$. Med. J. 1967 I, 84-88

10. Ellis, B. C., Stransky, A.: A quick and accurate method for the determination of fibrinogen in plasma. J. Lab. Clin. Med. 58, $477-488$ (1961)

11. Burmester, H. B. C., Aulton, K., Horsfield, G. I.: Evaluation of a rapid method for the determination of plasma fibrinogen. J. Clin. Pathol. 23, 43-46 (1970)

12. Ghanem, M. H., Tawfik, S., Guirgis, F. K.: Correlative study of blood coagulation and lipids in uncomplicated diabetes mellitus. Atherosclerosis 14, 271-281 (1971)

13. MacCuish, A. C.: In: Recent advances in intensive therapy. Ledingham, I. M. (ed.), Chapter 9: Diabetic hyperosmolar states, pp 107-124. Edinburgh: Churchill Livingstone 1977

Received: August 17, 1978,

and in revised form: June 22, 1979

Dr. E. H. McLaren

Division of Medicine

Stobhill General Hospital

Glasgow, G21 3UW

Scotland 